\title{
Produção de Soros Policlonais com Alta Afinidade contra o Biotipo 'C' e o Biotipo 'S' de Crinipellis perniciosa
}

\author{
Gildemberg A. Leal Júnior ${ }^{*}$, Keila M. R. Duarte², Paulo S. B. Albuquerque ${ }^{3}$, \\ Flávio C. A. Tavares ${ }^{2} \&$ Antonio Figueira ${ }^{1}$
}

${ }^{1}$ Laboratório de Melhoramento de Plantas, Centro de Energia Nuclear na Agricultura, Universidade de São Paulo, CEP 13400-970, Piracicaba, SP, email: galeal@cena.usp.br; ${ }^{2}$ Departamento de Genética, Escola Superior de Agricultura

“Luiz de Queiroz", Universidade de São Paulo, CEP 13418-900, Piracicaba, SP, ${ }^{3}$ Comissão Executiva do Plano da Lavoura Cacaueira, Ministério da Agricultura, Pecuária e Abastecimento, Cx. Postal 46, CEP 67105-970, Marituba, PA

(Aceito para publicação 07/07/2005)

Autor para correspondência: Gildemberg A. Leal Jr

LEAL JÚNIOR, G.A., DUARTE, K.M.R., ALBUQUERQUE, P.S.B., TAVARES, F.C.A. \& FIGUEIRA, A. Produção de soros policlonais com alta afinidade contra o biotipo ' $\mathrm{C}$ ' e o biotipo ' $\mathrm{S}$ ' de Crinipellis perniciosa. Fitopatologia Brasileira 30:482-488. 2005.

\section{RESUMO}

A obtenção de soros policlonais contra fitopatógenos tem por finalidade a elaboração de imunoensaios que permitam identificar e caracterizar os mesmos com rapidez e a custos baixos. Soros policlonais foram produzidos contra extratos das hifas de isolados de Crinipellis perniciosa, agente causal da vassoura-de-bruxa, coletados de cacaueiro (Theobroma cacao) nos estados do Pará e Bahia para identificação e caracterização de isolados de diversas regiões e hospedeiros. O soro denominado de 1 foi produzido a partir do isolado ESJOH-1 (originário do Pará), e o soro 2 foi produzido com o isolado CP-85 (originário da Bahia). Não houve reação cruzada dos soros contra extratos protéicos das espécies Alternaria solani, Marasmius sp., Oudemansiella canarii e Verticillium fungicola. Os soros apresentaram reação cruzada de alta afinidade com extratos de Moniliophthora roreri e de baixa a média afinidade com Marasmius cladophyllus. A caracterização dos isolados foi feita com amostras do biotipo-C coletados no Amazonas, Bahia, Mato Grosso, Rondônia e Pará. As reações sorológicas dos dois soros não permitiram diferenciar os isolados do Pará e da Bahia, contra os quais foram produzidos, e também não reagiram diferencialmente com isolados de outros estados. O reconhecimento dos antígenos entre os soros foi variável, pois o soro 1 e soro 2 apresentaram reação sorológica diferenciada para alguns isolados. Os soros produzidos apresentaram alta afinidade contra isolados dos biotipos-C e $\mathrm{S}$, independente de sua origem geográfica, podendo ser usados para identificação.

Palavras-chave adicionais: ELISA, Moniliophthora roreri, variabilidade, vassoura-de-bruxa, cacaueiro, Theobroma.

\begin{abstract}
Production of high affinity polyclonal sera against Crinipellis perniciosa biotypes ' $C$ ' and ' $S$ '

The production of polyclonal sera against plant pathogens allows the development of immunoassays to quickly identify and characterize the pathogens at low cost. Polyclonal sera were produced against Crinipellis perniciosa, the causal agent of witches' broom disease of cacao (Theobromae cacao) using hyphae extracts from isolates collected in Pará and Bahia states, to identify and distinguish isolates from various regions and hosts. Serum 1 was produced from isolate ESJOH-1 (collected in Pará) and serum 2, from isolate CP-85 (from Bahia). There was no cross reaction between the two sera with mycelia extracts from Alternaria solani, Marasmius sp., Oudemansiella canarii and Verticillium fungicola. The sera presented high affinity cross reaction with Moniliophthora roreri and medium- to low cross-reaction against Marasmius cladophyllus. The sera were evaluated against isolates from biotype-C, collected in the states of Amazonas, Bahia, Mato Grosso, Rondônia and Pará. The serological reaction of both sera did not allow to distinguish the isolates' site of origin (Pará and Bahia), nor did they differentiate isolates of biotype C. The antigen binding sites were different for serum 1 and 2, because both exhibited different response to the same strains. However, these differences in affinity did not allow for differentiating the origin of collection, host or biotype, but allowed for the identification of $C$. perniciosa belonging to biotypes $\mathrm{C}$ and $\mathrm{S}$.
\end{abstract}

Additional keywords: ELISA, Moniliophthora roreri, variability, witches' broom disease, cacao, Theobroma.

\section{INTRODUÇÃO}

A doença "vassoura-de-bruxa" do cacaueiro (Theobroma cacao L.), causada pelo basidiomiceto Crinipellis perniciosa (Stahel) Singer, representa um grande problema fitossanitário da cultura nas Américas, com imenso dano econômico. Crinipellis perniciosa estende sua gama de hospedeiros para outras espécies do gênero Theobroma, pelo menos T. bicolor Humb. \& Bonpl., T. grandiflorum (Willd ex. Spreng) Shum, T. microcarpum Bern., T. obovatum Klotzsch ex Bernoulli, T. subincanum Mart., e T. speciosum (Willd ex. Spreng), Herrania [(H. albiflora Goudot, H. nitida 
Poepp. e H. purpurea (Pittier) R. E. Schult e Sterculia (Evans, 1978)]. O fungo também infeta as espécies urucum (Bixa orellana L.), Capsicum frutescens L., pimentão (C. annuиm L.), Solanum rugosum Rich. ex Poir., S. lasiantherum Heurck \& Muell. Arg, S. paniculatum L., S. lycocarpum St. Hil., S. gilo Raddi, caiçara (S. stipulatum Willd. ex Roem \& Schutt), beringela ( $S$. melongena L.) e tomate (Lycorpersicon esculetum Mill.) (Bastos \& Evans, 1985; Bastos \& Andebrahn, 1986; Silva et al., 1992; Resende et al., 1998). Há relatos sobre esse fungo colonizando lianas da família Malpighiaceae nas espécies Heteropterys acutifolia A. Juss. (Resende et al., 2000) e Mascagania sepium A. Juss. (Bastos et al., 1998).

A "vassoura-de-bruxa" é endêmica na região Amazônica, sendo um dos maiores entraves para o desenvolvimento do cultivo do cacaueiro na América do Sul. A introdução da doença, ocorrida no sul da Bahia em 1989 causou sérios prejuízos à lavoura cacaueira, que utilizava, principalmente, variedades altamente suscetíveis (Pereira et al., 1989).

A grande variabilidade de hospedeiros do $C$. perniciosa permite separar os isolados em grupos de acordo com o gênero que infetam, denominados biotipos (Griffith \& Hedger, 1994). Desta forma, os isolados são caracterizados em três biotipos: o biotipo Cacau (biotipo-C), que tem como hospedeiro as espécies do gênero Theobroma, principalmente o T cacao; o biotipo Solanacea (biotipo-S) agrupando isolados que infetam as espécies da família Solanaceae, e o biotipo Liana (biotipo-L) com isolados que são encontrados em lianas e cipós das famílias Malpighiaceae e Bignoneaceae. O biotipo Bixa é considerado o quarto biotipo e foi relatado por Bastos \& Andebrahn (1986), mas não foi notificada a produção de basidiocarpos nos ramos infetados. Um quinto biotipo, o biotipo-H, foi sugerido por Griffith et al. (2003) reunindo isolados coletados de Heteropterys acutifolia A. Juss.

A análise de polimorfismo por restrição dos fragmentos amplificados das regiões codificadoras e espaçadores (ITS, internal transcribed spacer) do DNA ribossomal e mitocondrial (Arruda et al., 2003b) não detectou diferenças entre isolados dos biotipos $\mathrm{C} \mathrm{e} \mathrm{S}$. Entretanto, reações distintas de incompatibilidade somática entre os biotipos foram relatadas (Griffith et al., 2003). Estudos de diversidade genética baseados na análise de RAPD (Random Amplified Polymorphic DNA) (Yamada et al., 1998) e regiões repetitivas de DNA (ERIC-PCR) (Arruda et al., 2003a), indicaram diferenças entre os biotipos-C e $\mathrm{S}$, demonstrando maior polimorfismo no biotipo-C. Em geral, a patogenicidade cruzada entre os isolados dos biotipos não ocorre, mas há relatos de isolados do biotipo-S e biotipo-L induzindo sintomas em cacau (Silva et al., 1992; Resende et al., 2000; Lopes, 2001; Viana Junior, 2001), sugerindo que as divergências dos grupos por compatibilidade somática e marcadores moleculares não refletiriam a especificidade do fungo em infetar um hospedeiro. Andebrahn \& Furtek (1994), baseados em análise de RAPD com isolados de diferentes localidades e hospedeiros, observaram maior similaridade entre isolados mais próximos geograficamente, mesmo de diferentes hospedeiros, do que os coletados do mesmo tipo de hospedeiro de localidades distantes.

Entre os isolados do biotipo-C coletados da região amazônica, há predominância de duas populações diferenciadas pela patogenicidade ao Scavina 6 (Wheeler \& Mepsted, 1988), e que são distintos somaticamente, apresentando subgrupos de incompatibilidade em cada população (McGeary \& Wheeler, 1988). Os isolados de $C$. perniciosa da Bahia foram agrupados, por análise de RAPD, em duas populações que apresentaram características de patogenicidade e incompatibilidade somática semelhante à de duas populações da Amazônia brasileira, reforçando a idéia da possível introdução independente de isolados originados desta localidade (Andebrahn et al., 1999).

Métodos imunológicos, baseados em anticorpos específicos para antígenos correspondentes, têm sido aplicados para identificação e classificação de fungos e bactérias (Dewey et al., 1991). Entre as alternativas de anticorpos específicos, estão os soros policlonais (Kozlova et al., 2001). O objetivo desse trabalho foi produzir soros policlonais contra isolados do biotipo-C coletados de cacau da Bahia e Pará, utilizando extrato de hifas dicarióticas, seguido da utilização deste soro em teste ELISA para identificação e caracterização de isolados de C. perniciosa de diferentes localidades e hospedeiros.

\section{MATERIAL E MÉTODOS}

\section{Isolados de Crinipellis perniciosa e outros fungos}

Todos os isolados isolados neste estudo (Tabela 1) foram mantidos em meio batata-dextrose-agar $2 \%(\mathrm{BDA})$ à temperatura ambiente $\left(28^{\circ} \mathrm{C}\right)$. $\mathrm{O}$ micélio, crescido no meio líquido batata-dextrose, foi separado da fase líquida por filtração a vácuo, lavado três vezes com água destilada, armazenado a $-70{ }^{\circ} \mathrm{C}$ e liofilizado. O extrato proteico liofilizado do isolado de Moniliophthora roreri (Cif. \& Par) Evans et al. foi cedido pelo Dr. Gareth Wyn Griffith, University of Wales, Reino Unido e mantido a $-20{ }^{\circ} \mathrm{C}$.

\section{Extração de proteínas solúveis e preparo do antígeno para imunização}

As soluções de antígeno inoculadas nos animais foram preparadas com os isolados de cacau ESJOH-1 (Pará) e CP85 (Bahia) obtidos na ESJOH-CEPLAC, Marituba, PA, e no CEPEC-CEPLAC, Itabuna, BA, respectivamente. Dois gramas de micélio foram macerados em nitrogênio líquido e ressuspendidos em $25 \mathrm{ml}$ de tampão salino PBS $(8 \mathrm{~g} \mathrm{NaCl}$; $0,2 \mathrm{~g} \mathrm{KCl} ; 1,15 \mathrm{~g} \mathrm{Na}_{2} \mathrm{HPO}_{4} ; 0,24 \mathrm{~g} \mathrm{KH}_{2} \mathrm{PO}_{4}$ por litro, $\left.\mathrm{pH} 7,4\right)$. $\mathrm{O}$ extrato foi posteriormente centrifugado por $2 \mathrm{~min}$ a $2.000 \mathrm{~g}$ e o sobrenadante, com antígenos solúveis em PBS, foi coletado e armazenado a $-20{ }^{\circ} \mathrm{C}$.

\section{Imunização e produção do soro policlonal}

Cada solução de antígeno foi utilizada para imunizar três coelhas da raça Nova Zelândia de dois meses de idade, com injeções subcutâneas no dorso e nos membros inferiores. 
G.A. Leal Júnior et al.

TABELA 1 - Isolados de Crinipellis perniciosa e outras espécies de fungos utilizados

\begin{tabular}{|c|c|c|c|}
\hline Espécie & Código & Hospedeiro & Localidade \\
\hline \multirow[t]{34}{*}{ Crinipellis perniciosa } & ESJOH -1 & Theobroma cacao & Marituba/PA \\
\hline & ESJOH -2 & T. cacao & Ouro Preto/RO \\
\hline & ESJOH -3 & T. cacao & Belé m/PA \\
\hline & ESJOH -4 & T. cacao & Altamira/PA \\
\hline & ESJOH -5 & T. cacao & Medicilândia/PA \\
\hline & ESJOH -6 & T. cacao & Ariquemes/RO \\
\hline & ESJOH -7 & T. сасаo & Manaus/AM \\
\hline & ESJOH -8 & T. cacao & Ji-Paraná/RO \\
\hline & ESJOH -9 & T. cacao & Alta Floresta/MT \\
\hline & ESJOH -10 & T. subincanum & Belé m/PA \\
\hline & ESJOH - 11 & T. bicolor & Belém/PA \\
\hline & ESJOH -12 & T. grandiflorum & Belém/PA \\
\hline & $\mathrm{CP}-6$ & T. cacao & Bahia \\
\hline & $\mathrm{CP}-12$ & T. cacao & Bahia \\
\hline & $\mathrm{CP}-27$ & T. c acao & Bahia \\
\hline & $\mathrm{CP}-30$ & T. cacao & Bahia \\
\hline & $\mathrm{CP}-36$ & T. cacao & Bahia \\
\hline & $\mathrm{CP}-60$ & T. cacao & Bahia \\
\hline & CP-80 & T. cacao & Bahia \\
\hline & $\mathrm{CP}-85$ & T. cacao & Bahia \\
\hline & CP-93 & T. cacao & Bahia \\
\hline & CP-98 & T. cacao & Bahia \\
\hline & CP-102 & T.cacao & Bahia \\
\hline & CP-106 & T. cacao & Bahia \\
\hline & $\mathrm{CP}-21$ & T. cacao & Manaus/AM \\
\hline & $\mathrm{CP}-22$ & T. cacao & Altamira/PA \\
\hline & $\mathrm{CP}-23$ & T. cacao & Belé m/PA \\
\hline & CP-24 & T. cacao & Tomé-Açu/PA \\
\hline & CP -83 & Herrania & Bahia \\
\hline & CP-20 & Solanaceae & Bahia \\
\hline & $\mathrm{CP}-37$ & Solanum paniculatum & Bahia \\
\hline & CP-104 & Capsicum frutescens & Bahia \\
\hline & CP-114 & S. paniculatum & Bahia \\
\hline & CP-108 & Stigmaphyllon sp. & Bahia \\
\hline Oudemansiella canarii & CCB 214 & Desconhecido & \\
\hline O. Canarii & CCB 179 & Desconhecido & \\
\hline Marasmius cladophyllus & CCB 378 & Desconhecido & \\
\hline Marasmius Sp. & CCB 361 & Desconhecido & \\
\hline Alternaria solani & & Desconhecido & \\
\hline Verticillium fungicola & & Desconhecido & \\
\hline
\end{tabular}

A primeira imunização foi realizada no dorso e foi administrado o volume de $200 \mu \mathrm{l}$ da mistura de solução de antígeno $\left(100 \mu \mathrm{g} \cdot \mathrm{ml}^{-1}\right)$ com adjuvante completo de Freund (SigmaAldrich, St. Louis, MO, EUA) na proporção de 1:1, e a cada 15 dias foram repetidas imunizações injetando, via subcutânea, $200 \mu \mathrm{l}$ do extrato de antígeno em cada membro inferior. No total foram realizadas quatro imunizações e o sangue foi coletado antes de cada imunização e mantido a $37^{\circ} \mathrm{C}$ por 1 h. Posteriormente, o sangue foi centrifugado a $2.000 \mathrm{~g}$ durante 2 min e o sobrenadante, contendo o soro bruto, foi purificado em coluna de sefarose-proteína A (Affi-gel protein A agarose, Bio-Rad, Hercules, CA, EUA ), quantificado a $280 \mathrm{~nm}$ em espectrofotômetro e aliquotado.

\section{Preparo do extrato de micélio para imunoensaio}

Para todos os isolados de fungos disponíveis, o preparo dos extratos foi realizado de forma similar à dos extratos inoculados nos coelhos. Os extratos foram mantidos em alíquotas de $10 \mathrm{ml}$ e armazenados $\mathrm{a}-20{ }^{\circ} \mathrm{C}$.

\section{Ensaio imunoenzimático indireto (ELISA) do tipo PTA (plate trapped antigen)}

Placas de polivinil de fundo chato com 96 orifícios foram sensibilizadas com $100 \mu$ l do extrato do antígeno (100 $\mu \mathrm{g} . \mathrm{ml}^{-1}$ ) por orifício e incubadas por $1 \mathrm{~h}$ a $37^{\circ} \mathrm{C}$. Após a sensibilização, os sítios ativos remanescentes de cada orifício foram inativados com $200 \mu \mathrm{l}$ de tampão de bloqueio (PBS e $1 \%$ BSA, albumina sérica bovina) e a placa foi novamente incubada por $1 \mathrm{~h}$ a $37^{\circ} \mathrm{C}$. Para a próxima etapa do ELISA, o tampão foi descartado e em seguida foi adicionado $100 \mu \mathrm{lde}$ anticorpo $\left(1 \mu \mathrm{g} \cdot \mathrm{ml}^{-1}\right)$ contra $C$. perniciosa, adicionados às placas em três repetições e incubados por $1 \mathrm{~h}$ a $37^{\circ} \mathrm{C}$. Os 
orifícios foram então lavados com $200 \mu 1$ da solução contendo PBS, $0,5 \%$ Tween 20 e $0,25 \%$ Gelatina (PBS-T-G) por três vezes. A placa foi então seca e fez-se a incubação por $1 \mathrm{~h}$ a $37{ }^{\circ} \mathrm{C}$ com o conjugado anti-coelho (IgG) marcado com fosfatase alcalina. Após três lavagens com PBS-T-G conforme descrito anteriormente, a ação enzimática do conjugado foi ativada na presença do substrato $3 \mathrm{M}$ P-nitrofenil fosfatase (ImunPure PNPP, Pierce, Rockord, IL, EUA) em solução tampão (10 $\mathrm{mM}$ de dietanolamina e $0,05 \mathrm{M}$ de $\mathrm{MgCl}_{2} \mathrm{em}$ água). A leitura foi feita em leitor de microplacas modelo 550 (BioRad) a $405 \mathrm{~nm}$ após $1 \mathrm{~h}$ de reação. Os ensaios foram realizados separadamente para cada soro produzido. Os valores da absorbância obtidos para os isolados testados foram avaliados pelo programa estatístico SAS como experimento inteiramente casualizado, usando-se o teste Tukey para comparação de médias de três repetições. A afinidade do soro com os isolados foi analisada tendo como referência de alta afinidade a reação do soro com o isolado contra o qual foi produzido. Reações com outros isolados que representassem valores relativos de $40 \%$ e $70 \%$ do registrado para a referência foram consideradas como reações de média afinidade do soro, valores entre 20 e $40 \%$ fraca afinidade e inferiores que $20 \%$, afinidade nula.

\section{RESULTADOS E DISCUSSÃO}

Foram produzidos dois soros policlonais utilizando hifas dicarióticas de dois isolados do fitopatógeno $C$. perniciosa, que foram empregados em imunoensaios do tipo ELISA para identificação e caracterização de isolados coletados de diferentes localidades e hospedeiros. Os soros policlonais produzidos reconheceram antígenos do extrato de C. perniciosa demonstrando que imunizações em coelhos com extratos de hifas dicarióticas de C. perniciosa foram suficientemente alergênicas para produção de soro. Os dois soros policlonais foram produzidos contra os isolados ESJOH-1, originário do Pará, denominado de soro 1, e o outro contra o isolado CP-85, coletado na Bahia, denominado soro 2. Os dois soros também apresentaram reação positiva contra basidiósporos do fungo em ensaio ELISA, demonstrando a existência de antígenos comuns entre hifas dicarióticas e esporos meióticos (dados não mostrados).

As absorbâncias dos dois soros contra os próprios isolados com os quais foram produzidos serviram como referência para os ensaios ELISA. O soro 1 foi mais imunoreativo que o soro 2 contra os isolados ESJOH-1 e CP-85, sendo os valores de absorbância para o soro 1 superiores aos valores obtidos com o soro 2 (Tabela 2). No ensaio de ELISA utilizando os extratos de espécies saprófitas [Marasmius sp., M. cladophyllus Berk. e Oudemansiela canarii (Jungh.) v. Höhnel], os soros 1 e 2 não apresentaram reação cruzada contra as espécies $O$. canarii e Marasmius sp., pois os valores de absorbância não diferiram estatisticamente da leitura obtida com o branco (tampão PBS) (Tabela 2). A reação do soro 1 com M. cladophyllus foi considerada de fraca afinidade pois equivale a $17 \%$ da reação do soro 1 contra o isolado ESJOH-1 e o soro 2 apresentou uma afinidade mediana com M. cladophyllus, o valor de absorbância equivale a $45 \%$ da obtida com CP-85. Os soros produzidos apresentaram diferentes reações contra os extratos dos isolados ESJOH-1 e CP-85 e distinguem a espécie $C$. perniciosa das espécies dos gêneros Marasmius e Oudemansiella ambas da família Tricholomotaceae, a mesma família de C. perniciosa.

Soros policlonais produzidos especificamente contra patógenos também tem mostrado reações cruzadas com outros fungos que apresentam hospedeiros em comum (Holtz et al., 1994). Nos ensaios de ELISA para avaliação da especificidade, a reação cruzada dos soros foi observada com uma espécie de fungo patogênica ao cacau, M. roreri. Os isolados de Alternaria solani e Verticillium fungicola foram utilizados como controles negativos e os isolados de CP-85 e ESJOH-1 de cacau como controles positivos do ensaio. As reações dos soros contra as espécies $A$. solani e $V$. fungicola foram negativas, não diferenciando estatisticamente dos valores de absorbância obtidos com os isolados de $O$. canarii e Marasmius sp. (Tabela 2). Entretanto, contra a espécie $M$. roreri, os soros apresentaram alta afinidade, com valor de absorbância maior do que a obtida para a espécie $M$. cladophyllus e similar a registrada para C. perniciosa. O valor de absorbância obtido com soro 1 contra $M$. roreri representava $90,7 \%$ da leitura do isolado ESJOH-1 e a do soro 2 representava $75 \%$ da leitura registrada com o isolado CP-85. A forte afinidade dos soros com C. perniciosa e $M$. roreri provavelmente está associada a uma suposta estreita relação filogenética entre os gêneros. Evans et al. (2002; 2003) e Griffith et al. (2003) discutiram a classificação de $M$. roreri, baseado no estudo do ciclo biológico e da filogenia com seqüências de ITS, propondo a reclassificação do fungo M. roreri para Crinipellis roreri (Cif.) HC Evans. Os estudos do ciclo biológico indicam que a espécie $M$. roreri é um basidiomiceto e os estudos de filogenia demonstram alta

TABELA 2 - Valores de absorbância do ensaio de ELISA referente ao teste de reação cruzada dos soros policlonais 1 e 2 produzidos contra Crinipellis perniciosa e outras espécies de fungo

\begin{tabular}{lcc}
\hline \hline Espécie de fungo & Soro $1^{(*)}$ & Soro $2^{(*)}$ \\
\hline Crinipellis perniciosa $(\mathrm{CP}-85)$ & $2,008^{\mathrm{a}(* *)}$ & $1,077^{\mathrm{a}(* *)}$ \\
C. perniciosa (ESJOH -1) & $1,880^{\mathrm{b}}$ & $1,551^{\mathrm{b}}$ \\
Moniliophthora roreri & $1,705^{\mathrm{c}}$ & $0,815^{\mathrm{c}}$ \\
Marasmius cladophyllus (CCB 378) & $0,330^{\mathrm{d}}$ & $0,489^{\mathrm{d}}$ \\
Marasmius sp. (CCB 361) & $0,136^{\mathrm{e}}$ & $0,150^{\mathrm{e}}$ \\
Alternaria solani & $0,092^{\mathrm{e}}$ & $0,082^{\mathrm{e}}$ \\
Oudemansiella canarii (CCB 179) & $0,091^{\mathrm{e}}$ & $0,059^{\mathrm{e}}$ \\
O. canarii (CCB 214) & $0,079^{\mathrm{e}}$ & $0,073^{\mathrm{e}}$ \\
Verticillium fungicola & $0,085^{\mathrm{e}}$ & $0,074^{\mathrm{e}}$ \\
Branco (PBS) & $0,069^{\mathrm{e}}$ & $0,058^{\mathrm{e}}$ \\
\hline
\end{tabular}

(*) Valores representam a média de três repetições;

${ }^{(* *)}$ Valores seguidos pela mesma letra na coluna não diferem pelo teste Tukey $(\mathrm{p}>0,001)$. 
similaridade entre as seqüências de ITS das duas espécies (Evans et al, 2003). Reações cruzadas com alta afinidade de soros policlonais entre espécies do mesmo gênero são freqüentes (Delfosse et al., 2000) e neste estudo, indicam que o soro não é específico para a espécie C. perniciosa. A alta afinidade também pode ser atribuída ao fato de ambos compartilharem antígenos constitutivos em comum relacionados à interação patógeno-hospedeiro. Esta suposição é fundamentada nas seguintes características similares apresentadas pelos dois patógenos: especificidade ao cacau, ocorrência de uma fase biotrófica e indução de sintomas de hiperplasia no hospedeiro (Evans, 1981).

Nos ensaios de ELISA, conduzidos para a caracterização dos isolados de diversas localidades foram incluídos isolados do biotipo-C originários de cacau. Os isolados foram coletados das duas principais regiões produtoras de cacau do Brasil, tendo sido 12 coletados nos estados da região Norte e 12 de diferentes localidades do sul da Bahia, com exceção de um isolado originário da região Centro-Oeste (Tabela 3). Com o soro 1 , os valores de absorbância obtidos para os isolados da região Norte não diferiram estatisticamente entre si, não sendo possível separar pela afinidade do soro os isolados de Rondônia, Pará e Amazonas. Também não houve diferença entre os valores obtidos dos isolados da região Norte e dos isolados da Bahia; e destes com o isolado do Mato Grosso (Tabela 3). O soro 1 produzido contra o isolado do Pará, no ensaio de ELISA, apresentou uniformidade nos valores de absorbância e o soro 2, produzido contra o isolado da Bahia, também apresentou valores de absorbância uniforme, não sendo específico aos isolados da Bahia. Neste ensaio, foi verificado que o soro 2 tem menor poder discriminatório, pois apenas diferenciou estatisticamente um isolado, enquanto o soro 1 distinguiu quatro isolados no mesmo grupo. Os valores de absorbância do soro 2 quando comparados com o soro 1 também foram inferiores confirmando que o soro 2 é menos reativo que o soro 1 (Tabela $3)$. Os resultados indicaram que quatro isolados (CP-21, CP22, CP-27 e CP-80) apresentam antígenos reconhecidos pelos soros em quantidade reduzidas, que possibilitaram valores de absorbância diferenciados da maioria dos isolados. Esta variabilidade está presente nos isolados de ambas as regiões, estando entre os isolados de baixa afinidade espécimes coletados no Amazonas, Bahia e Pará.

A caracterização sorológica dos isolados também foi realizada com isolados do biotipo-C coletados de Herrania sp., T. bicolor, cacau, T. grandiflorum, T. subincanum; isolados do biotipo-S coletados de C. frutescens, $S$. paniculatum e de uma espécie não identificada da família Solanaceae. Um único isolado coletado de Stigmaphyllon sp. representa o biotipo-L (Tabela 3). Os dois soros não apresentaram afinidade com o biotipo-L (CP-108), sendo que o valor de absorbância foi similar aos registrados para as espécies $O$. canarii, Marasmius sp., A. solani e $V$. fungicola, contra os quais os soros não apresentaram reação cruzada (Tabela 2). O isolado CP-108 pode ser um isolado identificado erroneamente como C. perniciosa devido à falta de afinidade dos soros com este isolado. Nos ensaios de ELISA empregando o soro 1, os isolados do biotipo-S apresentaram valores que diferenciavam estatisticamente, distinguindo isolados coletados da mesma espécie de hospedeiros, CP-37 e CP-104 (Tabela 3). Com os isolados do biotipo-C, o soro 1 não apresentou diferença na afinidade para os isolados coletados de diferentes espécies de Theobroma e Herrania. $\mathrm{Na}$ avaliação utilizando o soro 2 apenas o isolado do biotipoS (CP-20) apresentou valor de absorbância significativamente diferente dos demais. Para os outros três isolados, os valores de absorbância não diferenciaram estatisticamente dos isolados do biotipo-C. Da mesma forma, não houve distinção para afinidade entre os isolados coletados das espécies de Theobroma e entre as espécies de Theobroma e Herrania. Entre os isolados do biotipo-S foi verificada uma variabilidade na constituição de antígenos reconhecidos pelo soro 1 , que também foi detectada entre os isolados do biotipo-C coletados de cacau. Esta variabilidade não é característica de um único biotipo, está presente entre os isolados coletados da mesma espécie de hospedeiro, sendo constatada nos isolados coletados de $S$. paniculatum e cacau. Para os demais hospedeiros, não foi possível verificar esta variabilidade por haver apenas um único isolado por hospedeiro.

Arruda et al. (2003b) diferenciaram por análise de IGS (intergenic spacer region) os isolados do biotipo-L, S e $\mathrm{C}$ em grupos filogeneticamentes distintos. Marcadores moleculares de regiões não codantes, do tipo RAPD e ERIC, também possibilitaram a distinção dos biotipos-S e C (Yamada et al., 1998; Arruda et al., 2003a), mas os soros não detectam esta distinção entre estes biotipos. A ausência de discriminação dos biotipos pelos soros se deve a diferenças constatadas por marcadores moleculares não refletirem a composição de antígenos, e que os soros policlonais produzidos contra extratos de proteínas totais de hifas abordam um amplo espectro de antígenos. Anticorpos monoclonais seriam uma abordagem alternativa de imunoensaio com maior especificidade.

Os dois soros não diferenciaram isolados do biotipo$\mathrm{C}$ das regiões norte e da Bahia, possivelmente ocasionado pela estreita similaridade genética entre os dois isolados. A introdução do patógeno na Bahia aconteceu por meio de dois materiais, provavelmente originado de duas localidades da Amazônia brasileira, identificados por análise de RAPD (Andebrahn et al., 1999), e corroborado por análise cariotípica por eletroforese em campo pulsado (Rincones et al., 2003). A introdução de grupos distintos e o isolamento geográfico destes materiais da região de origem não possibilitou, até o momento, a geração de isolados geográficos e a ocasional variação no padrão de antígenos produzidos. Arruda et al. (2003a; 2003b), utilizando marcadores moleculares do tipo IGS e ERIC-PCR, confirmaram a similaridade dos materiais das duas regiões e os agrupamentos formados com os isolados da Bahia não foram bem definidos e homogêneos. Os soros produzidos contra isolados das duas localidades demonstram que o padrão dos antígenos reconhecidos por ambos não difere os isolados dentro e nem 
TABELA 3 - Valores de absorbância (D.O) referente ao ensaio de ELISA para verificar a reatividade dos soros policlonais 1 e 2 contra isolados de Crinipellis perniciosa coletados de Theobroma cacao de diferentes localidades, e outras espécies de hospedeiros

\begin{tabular}{|c|c|c|c|c|c|c|c|}
\hline \multirow{2}{*}{ Código } & \multirow{2}{*}{ Hospedeiro } & \multirow{2}{*}{ Biotipo } & \multirow{2}{*}{ Localidade } & \multicolumn{2}{|c|}{ Soro 1} & \multicolumn{2}{|c|}{ Soro 2} \\
\hline & & & & D. (*) $^{(*)}$ & Afinidade $^{(* *)}$ & D.O (*) $^{(*)}$ & Afinidade $^{(* *)}$ \\
\hline $\mathrm{CP}-12$ & Theobroma cacao & Cacau & Bahia & $2,082^{\mathrm{a}(* * *}$ & *) +++ & $1,369^{\mathrm{a}(*}$ & $* * *)+++$ \\
\hline СР-60 & & Cacau & Bahia & $2,068^{\mathrm{a}}$ & +++ & $1,353^{\mathrm{a}}$ & +++ \\
\hline $\mathrm{CP}-24$ & & Cacau & Pará & $2,067^{\mathrm{a}}$ & +++ & $1,117^{\mathrm{a}}$ & +++ \\
\hline $\mathrm{CP}-23$ & & Cacau & Pará & $2,057^{\mathrm{a}}$ & +++ & $1,298^{\mathrm{a}}$ & +++ \\
\hline CP-98 & & Cacau & Bahia & $2,052^{\mathrm{a}}$ & +++ & $1,464^{\mathrm{a}}$ & +++ \\
\hline ESJOH -3 & & Cacau & Pará & $2,045^{\mathrm{a}}$ & +++ & $1,346^{\mathrm{a}}$ & +++ \\
\hline ESJOH -2 & & Cacau & Rondônia & $2,040^{\mathrm{a}}$ & +++ & $1,304^{\mathrm{a}}$ & +++ \\
\hline ESJOH -4 & & Cacau & Par & $2,039^{\mathrm{a}}$ & +++ & $1,363^{\mathrm{a}}$ & +++ \\
\hline CP-30 & & Cacau & Bahia & $2,037^{\mathrm{a}}$ & +++ & $1,321^{\mathrm{a}}$ & +++ \\
\hline $\mathrm{CP}-36$ & & Cacau & Bahia & $2,031^{\mathrm{a}}$ & +++ & $1,520^{\mathrm{a}}$ & +++ \\
\hline CP-93 & & Cacau & Bahia & $2,019^{\mathrm{a}}$ & +++ & $1,442^{\mathrm{a}}$ & +++ \\
\hline CP-106 & & Cacau & Bahia & $2,008^{\mathrm{a}}$ & +++ & $1,146^{\mathrm{a}}$ & +++ \\
\hline $\mathrm{CP}-85$ & & Cacau & Bahia & $2,008^{\mathrm{a}}$ & +++ & $1,077^{\mathrm{a}}$ & +++ \\
\hline $\mathrm{CP}-102$ & & Cacau & Bahia & $2,004^{\mathrm{a}}$ & +++ & $1,123^{\mathrm{a}}$ & +++ \\
\hline ESJOH -5 & & Cacau & Pará & $2,002^{\mathrm{a}}$ & +++ & $1,451^{\mathrm{a}}$ & +++ \\
\hline ESJOH -6 & & Cacau & Pará & $1,994^{\mathrm{a}}$ & +++ & $1,365^{\mathrm{a}}$ & +++ \\
\hline $\mathrm{CP}-6$ & & Cacau & Bahia & $1,983^{\mathrm{a}}$ & +++ & $0,920^{\mathrm{a}}$ & +++ \\
\hline ESJOH -7 & & Cacau & Amazonas & $1,973^{\mathrm{a}}$ & +++ & $1,323^{\mathrm{a}}$ & +++ \\
\hline ESJOH - 8 & & Cacau & Rondônia & $1,962^{\mathrm{a}}$ & +++ & $1,378^{\mathrm{a}}$ & +++ \\
\hline ESJOH -9 & & Cacau & Mato Grosso & $1,899^{\mathrm{a}}$ & +++ & $1,369^{\mathrm{a}}$ & +++ \\
\hline ESJOH -1 & & Cacau & Pará & $1,880^{\mathrm{a}}$ & +++ & $1,551^{\mathrm{a}}$ & +++ \\
\hline $\mathrm{CP}-27$ & & Cacau & Bahia & $1,696^{\mathrm{b}}$ & +++ & $1,364^{\mathrm{a}}$ & +++ \\
\hline $\mathrm{CP}-21$ & & Cacau & Amazonas & $1,006^{\mathrm{c}}$ & ++ & $0,726^{\mathrm{a}}$ & +++ \\
\hline CP- 80 & & Cacau & Bahia & $0,861^{\mathrm{d}}$ & ++ & $1,384^{\mathrm{a}}$ & +++ \\
\hline $\mathrm{CP}-22$ & T. cacao & Cacau & Pará & $0,650^{\mathrm{e}}$ & + & $0,457^{\mathrm{b}}$ & + \\
\hline CP-104 & Capsicum frutescens & Solanaceae & & $2,039^{\mathrm{a}}$ & +++ & $1,532^{\mathrm{a}}$ & +++ \\
\hline CP- 83 & Herrania & Cacau & & $2,035^{\mathrm{a}}$ & +++ & $1,617^{\mathrm{a}}$ & +++ \\
\hline CP -85 & T. cacao & Cacau & & $2,008^{\mathrm{a}}$ & +++ & $1,007^{\mathrm{a}}$ & +++ \\
\hline ESJOH - 10 & T. subincanum & Cacau & & $1,986^{\mathrm{a}}$ & +++ & $1,320^{\mathrm{a}}$ & +++ \\
\hline ESJOH -12 & T. grandiflorum & Cacau & & $1,917^{\mathrm{a}}$ & +++ & $1,243^{\mathrm{a}}$ & +++ \\
\hline $\mathrm{CP}-37$ & Solanum paniculatum & Solanaceae & & $1,987^{\mathrm{a}}$ & +++ & $1.297^{\mathrm{a}}$ & +++ \\
\hline ESJOH -11 & T. bicolor & Cacau & & $1,898^{\mathrm{a}}$ & +++ & $1,364^{\mathrm{a}}$ & +++ \\
\hline ESJOH -1 & T. cacao & Cacau & & $1,880^{\mathrm{a}}$ & +++ & $1,551^{\mathrm{a}}$ & +++ \\
\hline $\mathrm{CP}-20$ & Solanaceae & Solanaceae & & $1,298^{\mathrm{b}}$ & ++ & $0,887^{\mathrm{b}}$ & ++ \\
\hline $\mathrm{CP}-114$ & S. paniculatum & Solanaceae & & $0,490^{\mathrm{c}}$ & + & $1,492^{\mathrm{a}}$ & +++ \\
\hline CP-108 & Stigmaphyllon sp. & Liana & & $0,067^{\mathrm{d}}$ & 0 & $0,080^{\mathrm{c}}$ & 0 \\
\hline Branco (PBS) & & & & $0,065^{\mathrm{e}}$ & 0 & $0,075^{\mathrm{c}}$ & 0 \\
\hline
\end{tabular}

(*) Valores representam a média de três repetições;

(**) +++ indica alta, ++ média e + fraca afinidade dos soros com os extratos dos isolados;

(***) Valores seguidos pela mesma letra na coluna não diferem pelo teste Tukey $(\mathrm{p}>0,001)$.

entre as regiões, devido a grande similaridade genética, evidenciada por estudos com marcadores moleculares.

Este trabalho relata a obtenção de dois soros produzidos contra $C$. perniciosa e que também reconhecem antígenos presentes na espécie $M$. roreri (C. roreri) (Evans, 2002; Griffith et al., 2003). Os soros apresentam alta afinidade contra isolados do biotipo-S e contra os isolados do biotipo-C coletados em diversas localidades. Com estes soros, não foi possível a distinção sorológicas entre biotipos$\mathrm{S}$ e $\mathrm{C}$ e a diferenciação de isolados de origem geográficas distintas. A produção de anticorpos policlonais de amplo espectro que reconhecem $C$. perniciosa, viabiliza o uso de imunoensaios do tipo ELISA para quantificação de micélio em tecidos doentes ou a aplicação da técnica de imunolo- calização no estudo histológicos de tecidos infetados. Os soros por reagirem com basidiósporos podem ser utilizados, conjuntamente com anticorpos secundários marcados com fluoresceína, na identificação e contagem de esporos coletados em armadilhas caça-esporos ou realizando o ensaio ELISA com a suspensão de esporos recuperada das armadilhas.

\section{REFERÊNCIAS BIBLIOGRÁFICAS}

ANDERBRAHN, T., FIGUEIRA, A., YAMADA, M.M, CASCARDO, J. \& FURTEK. D.B. Molecular fingerprinting suggests two primary outbreak's of witches' broom disease (Crinipellis perniciosa) of Theobroma cacao in Bahia, Brazil. European Journal of Plant Pathology 105:167-175. 1999. 
ANDERBRAHN, T. \& FURTEK, D.B. Random amplified polymorphic DNA (RAPD) analyses of Crinipellis perniciosa isolates from different hosts. Plant Pathology 43:1020-1027. 1994.

ARRUDA, M.C.C., MILLER, R.N.G., FERREIRA, M.A.S.V. \& FELIPE, M.S.S. Comparison of Crinipellis perniciosa isolates from Brazil by ERIC repetitive element sequence-based PCR genomic fingerprinting. Plant Pathology 52:236-244. 2003a.

ARRUDA, M.C.C. de, FERREIRA, M.A.S.V., MILLER, R.N.G., RESENDE M.L.V. \& FELIPE M.S.S. Nuclear and mitochondrial rDNA variability in Crinipellis perniciosa from different geographic origins and hosts. Mycological Research 107:25-37. 2003b.

BASTOS, C.N. \& ANDERBRAHN, T. Urucum (Bixa orellana): nova espécie da Vassoura-de-Bruxa (Crinipellis perniciosa) do cacaueiro. Fitopatologia Brasileira 13:963-965. 1986.

BASTOS, C.N. \& EVANS, H.C. A new pathotype of Crinipellis perniciosa (witches' broom disease) on solanaceous hosts. Plant Pathology 34:306-312. 1985.

BASTOS, C. N., FONSECA, S.E.A. \& MELO, W.F. Mascagnia cf. sepium, native liana of the Brazilian Amazon, as host of Crinipellis perniciosa. Fitopatologia Brasileira 23:504. 1998 (Resumo).

DELFOSSE, P., REDDY, A.S., LEGERVE, A., DEVI, K.T., ABDURAHMAN, M.D., MARAITE, H. \& REDDY, D.V.R. Serological methods for detection of Polymyxia graminis, an obligate root parasite and vector of plant viruses. Phytopathology 90:537-545. 2000.

DEWEY, M., EVANS, D., COLEMAN, J., PRIESTlEY, R., HULL, R., HORSLEY, D. \& HAWES, C. Antibodies in plant science. Acta Botany Neerlandica 40:1-27. 1991.

EVANS, H.C. Witches' Broom disease of cocoa (Crinipellis perniciosa) in Ecuador: 1. The fungus. Annals of Applied Biology 89:185-192. 1978.

EVANS, H.C. Pod rot of cacao caused by Moniliophthora (Monilia) roreri. Phytopathological Papers 24:1-44. 1981.

EVANS ,H. C., HOLMES, K.A. \& REID, A.P. Phylogeny of the frosty pod rot pathogen of cocoa. Plant Pathology 52:476-485. 2003.

EVANS, H.C, HOLMES, K.A., PHILLIPS, W. \& WILKINSON, M.J. What's in a name: Crinipellis, the final resting place for the frosty pod rot pathogen of cocoa?. Mycologist 16:1-4. 2002.

GRIFFTH, G.W. \& HEDGER, J.N. The breeding biotypes of the witches' broom pathogen of cocoa, Crinipellis perniciosa. Heredity 72:278-289. 1994.
GRIFFITH, G.W., NICHOLSON, J., NENNINGER, A., BIRCH, R.N. \& HEDGER, J.N. Witches' broom and frosty pods in cacao. New Zealand Journal of Botany 41:423-435. 2003.

HOLTZ, B.A., KARU, A.E. \& WEINHOLD, A.R. Enzyme-linked immunosorbent assay for detection of Thielaviopsis basicola. Phytopathology 84:977-983. 1994.

KOZLOVA, N.V., STRUNNIKOVA, O.K., LABUTOVA, N.M. \& MUTOMTSEV, G.S. Production and specificity of polyclonal antibodies against soluble proteins from the arbuscular mycorrhizal fungus Glomus intraradices. Mycorrhiza 10:301-305. 2001.

LOPES, J.R.M., LUZ, E.D.M.N. \& BEZERRA, J.L. Suscetibilidade do cupuaçuzeiro e outras espécies vegetais a isolados de Crinipellis perniciosa obtidos de quatro hospedeiros diferentes do sul da Bahia. Fitopatologia Brasileira 26:601-605. 2001.

McGEARY, F.M. \& WHEELER, B.E.J. Growth rates of, and mycelial interaction between, isolates of Crinipellis perniciosa from cocoa. Plant Pathology 37:489-498. 1988.

RESENDE, M.L.V., REZENDE, D.V. \& BEZERRA, J.L. Variabilidade de Crinipellis sp. em diferentes hospedeiros no sul de Minas Gerais. Fitopatologia Brasileira 23:275. 1998 (Resumo). RESENDE, M.L.V., NOJOSA, G.B.A., SILVA, L.H.C.P., NIELLA, G.R., CARVALHO, G.A., SANTIAGO, D.V.R. \& BEZERRA, J.L. Crinipellis perniciosa proveniente de um novo hospedeiro, Heteropterys acutifolia, e patogênico ao cacaueiro. Fitopatologia Brasileira. 25:88-91. 2000.

RINCONES, J., MEINHARDT, L.W., VIDAL, B.C. \& PEREIRA, G.A.G. Electrophoretic karyotype analysis of Crinipellis perniciosa, the causal agent of witches' broom disease of Theobroma cacao. Mycological Research 107:452-458. 2003.

SILVA, S.D.V.M., GRAMACHO, K.P. \& ALMEIDA, O.C. Solanum paniculatum hospedeiro de Crinipellis perniciosa na região sul da Bahia. Agrotrópica 4:17-20. 1992.

VIANA JUNIOR, C.A.C. Compatibilidade somática e patogenicidade de Crinipellis sp. (Tese de Mestrado). Lavras. Universidade Federal de Lavras. 2001.

YAMADA, M.M., ANDERBRAHN, T. \& FURTEK, D.B. Genetic variability among isolates of Crinipellis perniciosa from solanaceous hosts and their relationship to isolates from Theobroma cacao. Agrotrópica 10:123-126. 1998.

WHEELER, B.E.J. \& MEPSTED, R. Pathogenic variability amongst isolates of Crinipellis perniciosa from cocoa (Theobroma cacao). Plant Pathology 37:475-488. 1988. 